\title{
MALIGNANT THYROID DISEASE; HYPOCALCAEMIA FOLLOWING THYROID SURGERY
}

\footnotetext{
1. FCPS

Associate Professor

Surgery unit - IV

LUMHS, Jamshoro.

2. MBBS,

Senior Medical Officer

NMC Specialty Hospital Abu Dhabi,

UAE.

3. FCPS, MS

Assistant Professor Surgery

LUMHS, Jamshoro.

4. MBBS,

MPH student

Icahn School of Medicine

Mount Sinai, Newyork, USA

5. FCPS (Professor)

Incharge Surgical Unit - IV

LUMHS Jamshoro.

6. FCPS (General Surgery)

Ex-Professor of Surgery

Peoples Medical College,

Nawabshah.
}

Correspondence Address:

Dr. Altaf Ahmed Talpur

Flat No: 504, Shaia's Apartments

Main Jamshoro Road, off Citizen

Colony

Hyderabad, Pakistan.

altafktalpur@yahoo.com

Article received on:

20/02/2017

Accepted for publication:

15/09/2017

Received after proof reading:

29/11/2017

\section{INTRODUCTION}

Tetany and recurrent laryngeal nerve injury are the two most common \& ancient complications of thyroid surgery. ${ }^{1}$ Initially clinical features of Hypocalcaemia were considered to be due to deficiency of thyroid hormones secondary to thyroid gland surgery. However it was diagnosed as features secondary to Hypocalcaemia due to Parathyroid deficiency when these patients were treated with extracts of parathyroid gland. In their studies they reported $24 \%$ of their cases developed Hypocalcaemia due to deficiency of Parathyroid hormone following thyroid surgery. ${ }^{2}$

Immediate clinical manifestations of hypocalcaemia include nerve and muscle
Altaf Ahmed Talpur ${ }^{1}$, Bheesham Kumar ${ }^{2}$, Ahsan Ali Laghari ${ }^{3}$, Abdul Qadeer Shikh ${ }^{4}$, Afzal Junejo ${ }^{5}$, Ali

ABSTRACT... Objectives: To determine frequency of Transient \& permanent hypocalcemia after Thyroid Surgery for Malignant thyroid disease. Study Design: Observational study. Setting: Public \& Private Sector Hospitals of Hyderabad. Period: December 2008 to April 2016. Materials and Methods: All patients of Thyroid pathology who fulfilled the inclusion criteria were admitted in the ward. They were evaluated preoperatively \& surgery was performed. ded \& analyzed for variables like age, sex, diagnosis of thyroid disease on FNAC relation to type of type of thyroid surgery performed \& the hospital stay. Results: Total 254 were diagnosed as Malignant Thyroid diseases. Most common ollicular carcinoma in $42.42 \%$ patients. Most common surgical procedures performed includes thyroidectomy in $57.57 \%$ patients with $01(3.03 \%)$ of them underwent cervical ( to 48 hours \& $3.03 \%$ patients after 48 hours of surgery. Transient hypocalcemia was noticed in $13 / 33(39.39 \%)$ cases \& permanent hypocalcemia in 02/33(6.06\%) patients. Mean hospital stay was $4.13 \pm 0.32$ days. Conclusion: Hypocalcaemia was noted in 15(45.45\%) patients operated for thyroid Malignancy. Revision surgery \& cervical lymph node dissection were noted as risk factors.

Key words: $\quad$ Thyroid Malignancy/Surgery/Hypocalcemia. thyroid disease; hypocalomia following thyroid Med J 2017;24(12):1794-1800. DOI:10.17957/TPMJ/17.3894

symptoms but occasionally psychotic symptoms may be observed. Persistent hypocalcaemia causes disability and a considerable financial loss due to adverse impact on health of patient. ${ }^{3}$ Delbridge $L$ described technique of capsular dissection of thyroid gland to reduce the chances of permanent hypocalcemia. ${ }^{4}$ Puzziello A et al in their study on 2631 patients reported $0.4 \%$ patients operated for thyroid developed permanent hypocalcemia. ${ }^{5}$

Intra operative assay of parathyroid hormone (PTH) predicts risk of hypocalcemia successfully after thyroid surgery as reported by Wang $\mathrm{J}$ et al in their study. ${ }^{6}$ 
Noticeable risk factors of hypocalcemia following thyroid surgery include; large goiters, recurrent goiter, retrosternal goiter extension, hyperthyroidism, total thyroidectomy and experience of the surgeons. ${ }^{7,8}$

The present study was intended to find out the frequency of Hypocalcemia in patients operated for malignant thyroid surgery. It includes risk associated with the extent of surgery \& severity of Hypocalcemia.

\section{MATERIALS \& METHOD}

The present observational study was conducted at public \& private sector hospitals of Hyderabad from December 2008 to April 2016. It includes all patients of either sex above the age of 13 years who underwent different surgical procedures for malignant thyroid diseases. All patients of both sex with age under 13 years, or patients with inoperable thyroid malignancy like stage III or IV thyroid malignancy or patients having clinical or subclinical symptoms \& signs of Hypocalcaemia or biochemical measurement show low levels of serum calcium preoperatively or altered serum Albumin levels were excluded. Patients receiving $\mathrm{Ca}++$ supplements, multivitamins and mineral formulas were also excluded. Patient's didn't attended follow-up clinics or consented for study was also excluded.

Pre-operative clinical work up included patient's history, examination of thyroid gland \& Neck. Patients were also assessed clinically for symptoms \& signs of hypocalcemia. Investigations performed include thyroid hormone profile, serum $\mathrm{Ca}++$ level, serum albumin level, ultrasound of Neck \& thyroid gland and FNAC of thyroid swelling or where required thyroid scan was performed. In cases with proven preoperative malignancy of thyroid staging workup was also performed. Indirect laryngoscopy (IDL) was performed preoperatively for vocal cord movement. Diagnosis was made.

Thyroid surgery was planned by surgical team under general anesthesia. Lateral mobilization was performed by capsular dissection technique for parathyroid glands and recurrent laryngeal nerve. Cervical Lymph nodes dissection was made as necessary depending upon the type of Malignancy \& presence or absence of enlarged cervical lymph nodes. Postoperatively patients were assessed clinically for circumoral tingling, numbness of fingers \& toes, apprehension, seizures \& carpopedal spasm as well as biochemically for hypocalcemia. Postoperatively serum calcium level measurement was performed on all patients on first postoperative day \& afterwards if patient developed clinical features of Hypocalcemia on subsequent days. If patient developed clinical features of Hypocalcemia on same postoperative day, serum calcium measurement was performed in that patient on same day. Hypocalcaemia was defined as calcium level $<8 \mathrm{mg} / \mathrm{dl}$. If hypocalcemia was confirmed postoperatively, it was treated as per standard protocol. In severe cases $40 \mathrm{MEq}$ of intravenous calcium gluconate diluted in 100 of normal saline was administered. Follow-up visits were advised at 01 week, 01 month for 03 months \& then every 03 months for 01 year. Patients were briefed about the diagnosis and procedure to be performed. Patients were informed and permission was granted. They were assured that their participation is voluntary with no harms to them in terms of getting due treatment. They were also given right to withdraw from study without putting any reasons.

Patient's data was recorded on a preformed proforma. Data was analyzed for categorical and continuous variables like age, sex, diagnosis of thyroid disease on FNAC, Type of thyroid Malignancy, type of thyroid surgery, Transient \& permanent hypocalcemia in relation to type of type of thyroid surgery performed \& the hospital stay. Specific statistical tests were applied \& Pvalue was calculated. P-value less than 0.05 were considered significant. All analysis was done using SPSS 16.

\section{RESULTS}

During this period, total of 254 patients were operated for different thyroid pathologies. It includes 91(35.82\%) male \& and 163 (64.17\%) female patients making male to female ratio of 1: 1.79. Mean age of this group of patients was 
37.29 years with SD of \pm 7.4 years \& range of 24 -67 years.

Amongst 254 operated patients for thyroid pathology, 33 patients were diagnosed as cases of Malignant Thyroid diseases. It includes $13(39.39 \%)$ patients who were diagnosed as cases of papillary carcinoma of thyroid on FNAC preoperatively while remaining $20(60.60 \%)$ patients were found as cases of Malignant Thyroid diseases on histopathological evaluation of thyroid specimens postoperatively.

Operative procedures performed on 13(39/39\%) patients with preoperative diagnosis of Papillary carcinoma of thyroid on FNAC include Total thyroidectomy in $10(30.30 \%)$ patients, total thyroidectomy with cervical lymph node dissection in $02(6.06 \% \%)$ patients while in $01(3.03 \%)$ patient thyroid Lobectomy was performed as tumor size was less than $1.5 \mathrm{~cm}$ on pre \& per operative evaluation. Biopsy of resected specimens confirmed diagnosis of papillary carcinoma of thyroid.

In remaining $20(60.60 \%)$ patients, Thyroid Lobectomy was performed as initial procedure as diagnosis was not confirmed on FNAC \& specimens were sent for histopathology. It confirmed diagnosis of follicular carcinoma in $14(42.42 \%)$ patients, papillary carcinoma in $03(9.09 \%)$ patients, Hurthle cell variant of follicular neoplasm in $02(6.06 \%)$ patients \& medullary carcinoma in $01(3.03 \%)$ patient. All these patients underwent completion thyroidectomy except $01(3.03 \%)$ patient of Papillary carcinoma in which no further procedure was performed due to small size of tumor i-e less than $1.5 \mathrm{~cm}$. Also $01(3.03 \%)$ patient of papillary carcinoma thyroid underwent cervical lymph node dissection along with completion thyroidectomy.

Decreased serum calcium level was noted in $15(45.45 \%)$ patients with $11(33.33 \%)$ of them had evident clinical features of Hypocalcemia, 03(9.09\%) had incipient Hypocalcemia which appeared on application of different clinical signs on 1st Postoperative day \& afterwards. While remaining $01(3.03 \%)$ patient had no clinical symptoms or a sign of hypocalcemia but hypocalcemia was recognized on measurement of serum calcium level on $1^{\text {st }}$ postoperative day as routine. Amongst the 14(42.42\%) patients who developed evident or incipient clinical features of Hypocalcemia, $10(30.30 \%)$ developed within 24 hours with $02(6.06 \%)$ of them developed this within 06 hours after surgery, 03(9.09\%) patients within 24 to 48 hours \& 01 (3.03\%) patients after 48 hours.

All patients with decreased calcium level were put on calcium \& vitamin D3 therapy. 11(33.33\%) patients with evident clinical features of Hypocalcemia were initially put on intravenous calcium treatment \& then switched to oral treatment once clinical features of hypocalcemia settled down. Remaining 04(12.12\%) patients of asymptomatic hypocalcemia were kept on oral therapy of calcium. All these patients were also given vitamin D3 therapy.

$13(39.39 \%)$ patients responded to therapy \& on $05^{\text {th }}$ postoperative day calcium therapy was stopped. However 02(6.06\%) of them developed recurrent hypocalcemia \& were put on oral calcium \& vitamin D3 therapy until they settled down. In 02(6.06\%) patients, clinical features of hypocalcemia did not settled down on calcium \& vitamin D3 supplement for 06 weeks consecutively \& were declared as cases of permanent hypocalcemia. These 02(6.06\%) patients include $01(3.03 \%)$ patient each of total thyroidectomy \& completion thyroidectomy with cervical lymph node dissection.

Mean duration of hospital stay was $4.13 \pm 0.32$ days.

\begin{tabular}{|c|c|}
\hline $\begin{array}{l}\text { Type of Thyroid operation } \\
\text { Total Thyroidectomy }\end{array}$ & No: \& \% of patients \\
\hline $\begin{array}{l}\text { Total Thyroidectomy with } \\
\text { Cervical lymph nodes dissection }\end{array}$ & $02(6.06 \%)$ \\
\hline $\begin{array}{l}\text { Thyroid Lobectomy } \\
\text { Completion Thyroidectomy }\end{array}$ & $02(6.06 \%)$ \\
\hline $\begin{array}{l}\text { Completion Thyroidectomy with } \\
\text { cervical lymph nodes dissection }\end{array}$ & $01(3.03 \%)$ \\
\hline $\begin{array}{l}\text { Total } \\
\text { Table I. Different types of Thyroid operations in } \\
\text { Patients with Malignant Thyroid disease }(\mathrm{n}=33)\end{array}$ \\
\hline
\end{tabular}




\begin{tabular}{|l|c|c|c|c|}
\hline \multicolumn{1}{|c|}{ Type of operation } & \multicolumn{3}{c|}{ No: \& $\%$ of patients developed Hypocalcemia } \\
\hline & $\begin{array}{c}\text { Within } \mathbf{2 4} \\
\text { hours }\end{array}$ & $\begin{array}{c}\mathbf{2 4 - 4 8} \\
\text { hours }\end{array}$ & $\begin{array}{c}\text { After } \\
\text { hours }\end{array}$ & Total \\
\hline Total Thyroidectomy(10) & $04(12.12 \%)$ & $01(3.03 \%)$ & 00 & $05(15.15 \%)$ \\
\hline Total Thyroidectomy with cervical lymph node dissection (02) & $01(3.03 \%)$ & 00 & 00 & $01(3.03 \%)$ \\
\hline Completion Thyroidectomy(18) & $06(18.18 \%)$ & $01(3.03 \%)$ & $01(3.03 \%)$ & $08(24.24 \%)$ \\
\hline Completion Thyroidectomy with cervical lymph node dissection(01) & $01(3.03 \%)$ & 00 & 00 & $01(3.03 \%)$ \\
\hline Thyroid Lobectomy(02) & 00 & 00 & 00 & 00 \\
\hline Total (33) & $12(36.36 \%)$ & $02(6.06 \%)$ & $01(3.03 \%)$ & $15(45.45 \%)$ \\
\hline
\end{tabular}

Table II. Postoperative Hypocalcemia within 24 hours, between 24 to 48 hours \& after 48 hours of thyroid surgery According to type of operation

\section{DISCUSSION}

Present study is one of the recently conducted and reported studies on frequency of hypocalcemia after thyroid surgery in malignant thyroid disease \& it was found to be $45.45 \%$ from Liaquat University Hospital. Most common type of thyroid malignancy detected was papillary carcinoma in $48.48 \%$ patients followed by follicular carcinoma in $42.42 \%$ patients. In this study hypocalcemia was noted in $45.45 \%$ patients operated for malignant thyroid disorders.

Rosato $\mathrm{L}$ et $\mathrm{al}^{9}$ from Italy mentioned analysis of multicentric study of 14,934 cases of thyroid surgery operated over the period of 05 years. It includes $13 \%$ patients with malignant thyroid pathology with $91 \%$ belonged to differentiated thyroid carcinoma, $5 \%$ to Medullary carcinoma and $4 \%$ to undifferentiated carcinoma patients. Various studies from India showed that $76 \%$ of thyroid surgeries are conducted for the benign thyroid disorders such as nodular goiters, recurrent nodular goiters, retrosternal goiters, toxic Multinodular goiter and Grave`s disease. ${ }^{10}$

Baldassarre RL et al ${ }^{11}$ in their nationwide study of 119,567 thyroidectomy patients from 1998-2008 mentioned postoperative hypocalcemia in 5.5\% of all thyroidectomy patients before discharge. They include patients of all thyroid pathologies, not just malignant thyroid. Study by Rosato $L$ et al ${ }^{9}$ noticed postoperative transient hypocalcemia in $11.50 \%$ patients with malignant thyroid disease with permanent hypocalcemia was seen in $3.25 \%$ patients. Study by Page $\mathrm{C}$ et $\mathrm{al}^{12}$ in their study of 351 cases who underwent total thyroidectomy have reported postoperative hypocalcemia in $0.5 \%$ to $75 \%$ of the patients. ${ }^{12}$ Goncalves AJ et al ${ }^{13}$ in their study at Cancer Hospital in Brazil mentioned transient hypocalcemia in $13.1 \%$ patients \& permanent hypocalcemia in $2.5 \%$ patients among 1020 patients who underwent thyroidectomy.

Post-operative hypocalcemia may turn into a serious complication requiring close monitoring and calcium infusions to get rid of the clinical symptoms. Symptoms of post-operative hypocalcemia usually occur in the first 24 to 48 hours. ${ }^{3,8}$ Improvements in surgical technique have significantly decreased the complications associated total thyroidectomy. Despite it, postoperative hypocalcemia is still regarded as frequently encountered complication presenting as Tetany in the postoperative period. ${ }^{7}$ Literature also mention the experience of surgeon, retrosternal extension of thyroid, type of thyroidectomy, neck dissection and paratracheal lymph node dissection as key factors for postoperative hypocalcemia as mentioned by Mirkine ND et al 14 in their study.

Most common surgical procedures performed in this study includes completion thyroidectomy in $19(57.57 \%)$ patients with $01(3.03 \%)$ of them also underwent cervical neck dissection followed by total thyroidectomy in $12(36.36 \%)$ patients with $02(6.06 \%)$ of them underwent cervical neck dissection. Hypocalcemia was noticed in $08 / 18(44.44 \%)$ patients of completion thyroidectomy, in $05 / 10(50 \%)$ patients of total thyroidectomy, $02 / 03(66.66 \%)$ patients who underwent cervical lymph node dissection along with total \& completion thyroidectomy indicating extensive surgery poses higher risk of developing hypocalcemia. Of the $02(6.06 \%)$ 
patients of papillary carcinoma thyroid who underwent Lobectomy, none of them developed hypocalcemia.

In their study by Rosato $\mathrm{L}$ et $\mathrm{al}^{9}$ they mentioned 9599 (64.3\%) total thyroidectomies, 3130 (20.9\%) total lobectomies, 1448 (9.7\%) subtotal thyroidectomies with a monolateral remnant, and $757(5.1 \%)$ subtotal thyroidectomies with bilateral remnants. Among all the patients, 14,057 (94\%) were operated on for the first time, and there were 877 (6\%) reoperations. They noticed symptomatic hypocalcemia in $10.0 \%$ with $8.3 \%$ had transient \& $1.7 \%$ had definitive hypocalcemia which accounts for $63 \%$ of all complications. Amongst them transient \& permanent Hypocalcemia was seen in $0.4 \% \& 0.07 \%$ patients after Lobectomy, in $14 \% \& 2.2 \%$ cases after total thyroidectomy and in $5 \% \& 0.6 \% \& 0.8 \%$ patients after subtotal thyroidectomies with a monolateral remnant and subtotal thyroidectomies with bilateral remnants respectively. The incidence of postoperative permanent hypocalcemia after malignant thyroid cancer in their study was significantly higher (3.3\%).

lqbal et $\mathrm{al}^{15}$ from study in Pakistan on patients operated for malignant thyroid diseases reported hypocalcemia in $21.6 \%$ patients after total thyroidectomy. Study by Rosato $\mathrm{L}$ et $\mathrm{al}^{9}$ mentioned $11.75 \%$ \& $2.25 \%$ patients developed transient \& permanent hypocalcemia after total thyroidectomy, $0.5 \%$ \& 0 after Lobectomy, $4.6 \%$ \& $0.4 \%$ after subtotal thyroidectomy with monolateral residue \& $4.1 \%$ \& $0.9 \%$ after subtotal thyroidectomy with bilateral residue. Study by Tredici $\mathrm{P}$ et $\mathrm{al}^{16}$ from Italy mentioned postoperative hypocalcemia in $9.0 \%$ patients with total thyroidectomy, in $1.9 \%$ following unilateral thyroid Lobectomy, $14.4 \%$ following thyroidectomy plus unilateral neck dissection, $23.4 \%$ following thyroidectomy plus bilateral neck dissection, $9.6 \%$ following complete substernal thyroidectomy, $3.4 \%$ following partial substernal thyroidectomy, $6.5 \%$ following substernal thyroidectomy, and $3.4 \%$ following isthmectomy or otherwise unspecified partial thyroidectomy. Goncalves $\mathrm{AJ}$ et $\mathrm{al}^{13}$ in their study at Sao Paulo mentioned unilateral subtotal thyroidectomy associated with contralateral hemithyroidectomy was the most prevalent surgical resection causing hypocalcemia. It occurred in $66.6 \%$ of the cases followed by total thyroidectomy in $53.4 \%$ and by bilateral subtotal thyroidectomy in $35.3 \%$ cases. In their study the incidence of hypocalcemia in patients with malignant disease was higher $(60.7$ percent) than those with benign disease (46.4 percent). Jisheng $\mathrm{Hu}$ et $\mathrm{al}^{17}$ in their study on 5559 patients mentioned correlative incidence of transient \& permanent hypocalcemia in patients who were operated for first time of thyroid surgery \& in patients who underwent revision surgery. They found temporary hypocalcemia in $3.53 \%$ patients \& permanent hypocalcemia in $0.02 \%$ patients in first time surgery on thyroid while $13.76 \%$ \& $1.59 \%$ patients developed transient \& permanent hypocalcemia respectively in revised surgery group. In first time surgery group, transient \& permanent hypocalcemia was noticed in $3.28 \%$ \& $0.02 \%$ patients after total thyroidectomy, $2.18 \% \& 0$ in patients of hemithyroidectomy, $8.75 \%$ \& 0 in patients of total thyroidectomy with central neck dissection group \& 9.26\% \& $0.02 \%$ patients of total thyroidectomy with mono neck dissection. In the revised surgery group transient hypocalcemia \& permanent hypocalcemia was noticed in $1.38 \%$ \& $2.17 \%$ patients who underwent completion thyroidectomy after subtotal thyroidectomy \& in $1.96 \%$ \& 0 patients who underwent contralateral thyroidectomy after hemithyroidectomy at first surgery. Jong-Lyel $\mathrm{R}$ et $\mathrm{al}^{18}$ in their study mentioned morbidity and hypocalcemia was higher in the node dissection group than the no node dissection group \& serum PTH levels significantly decreased immediately postoperatively in the node dissection group and remained low for several weeks thereafter.

In this study $36.36 \%$ patients developed hypocalcemia within 24 hours of operation on thyroid, $6.06 \%$ within 24 to 48 hours of surgery \& $3.03 \%$ patients after 48 hours of surgery. MirkineND et $\mathrm{al}^{14}$ in their study reported Hypocalcemia in 54\% patients within the first 24 hours postoperatively with $40 \%$ of them had symptomatic hypocalcemia. Study by Nair et $\mathrm{al}^{3}$ has reported a frequency of Hypocalcemia in $23 \%$ subjects. Nair et $\mathrm{al}^{3}$ further reported onset of hypocalcaemia within 6 hours 
in $11.05 \%$ patients and was delayed up to $3^{\text {rd }}$ post operative day in $6.84 \%$. Tredici $\mathrm{P}$ et $\mathrm{al}^{16}$ reported that $50(50 \%)$ patients of their patients developed postoperative hypocalcemia with $24(48 \%)$ of them had symptomatic hypocalcemia \& 26(52\%) had asymptomatic hypocalcemia. Amongst them $12.5 \%$ had on the first day after surgery. $62.5 \%$ on the second day, $17 \%$ on the third day and $4 \%$ each on the fourth and fifth days.

In this study transient hypocalcemia was noticed in 13/33 (39.39\%) cases \& permanent hypocalcemia in $02 / 33(6.06 \%)$ patients. These 02(6.06\%) patients include one patient of total thyroidectomy \& other patient of completion thyroidectomy with cervical lymph node dissection. lqbal et $\mathrm{al}^{15}$ reported transient hypocalcemia in all cases.

Risk of getting permanent hypocalcemia varies with the type of surgery, expertise of operating surgeon. Lower chances of developing hypocalcemia have been noticed in highly specialized centers of thyroid pathology.

Analysis of Parathyroid hormone level 1 to 6 hours after thyroidectomy has significant accuracy in determining the chances of developing symptoms of hypocalcemia. Its routine measurement may help in earlier discharge of these patients and also early identification of developing hypocalcemia that may be instituted early treatment of post thyroidectomy hypocalcemia. ${ }^{19}$

Jong-Lyel $\mathrm{R}$ et $\mathrm{a}^{20}$ in their study of 197 patients operated for differentiated papillary thyroid carcinoma with 49 of them underwent total thyroidectomy alone and 148 underwent total thyroidectomy plus central neck dissection. Patients with neck dissection were randomized into 03 groups with Group A received oral calcium plus vitamin D, group B received only calcium, Group C received no supplemental therapy. Amongst them Group C patients developed significantly higher incidence of hypocalcemia which can be prevented by routine postoperative supplementation with oral calcium and vitamin D.

In this study mean duration of hospital stay was $4.13 \pm 0.32$ days while Mirkine ND et al $^{14}$ mentioned this as $3.33 \pm 3.09$ days for hypocalcemic patients and $1.85 \pm 3.55$ days for normocalcemic patients. Tredici $\mathrm{P}$ et $\mathrm{al}^{16}$ found hospital stay of 6.19 days \pm 0.24 days.

\section{CONCLUSION}

Relatively low number of Malignant thyroid disease $(12.99 \%)$ was noticed in this study with incidence of hypocalcemia was $45.45 \%$ in all operations performed for malignant thyroid disorder. Repeat surgery on thyroid with more extensive dissection predisposes the patient to develop hypocalcemia.

\section{Limitations of the study}

Non measurement of vitamin $D$ level and parathyroid hormone level due to cost and funding issues.

Copyright (C) 15 Sep, 2017.

\section{REFERENCES}

1. Fortuny VJ, Guigard S, Karenovics W, Triponez R. Surgery of the thyroid: Recent developments and perspective. Swiss Medical Weekly 2015; 1451: 141 44.

2. Michie W, Stowers JM, Frazer SC, Gunn A. Thyroidectomy and the Parathyroids. Br J Surg 1965; 52: 503-14.

3. Nair CG, Babu MJ, Menon R, Jacob P. Hypocalcaemia following total thyroidectomy: An analysis of $\mathbf{8 0 6}$ patients. Indian J Endocr Metab 2013; 17:298-303.

4. Delbridge LW. Total Thyroidectomy: The evolution of surgical technique. ANZ J Surg 2003; 73:761- 8.

5. Puzziello A, Rosato L, Innaro N, Orlando G, Avenia N, Perigli G, Calo PG, et al. Hypocalcemia following thyroid surgery: incidence and risk factors. A longitudinal multicenter study comprising 2,631 patients. Endocrine 2014; 47:537-542.

6. Wang J, Gu J, Han Q, Wang W, Shang J. Value of intra operative parathyroid hormone monitoring in papillary thyroid cancer surgery: Can it be used to guide the choice of operation methods? Int J Clin Exp Med 2015; 8(5):7778-7785.

7. Bliss RD, Gauger PG. Delbridge LW. Surgeon's approach to thyroid gland- Anatomy and surgical technique. World J Surg 2011; 24:891- 7.

8. Salinger EM and Moore JT. Perioperative indicators of hypocalcemia in total thyroidectomy: the role of 
vitamin D and parathyroid hormone. Am J Surg 2013; 206: 876 - 881.

9. Rosato L, Avenia N, Bernante P, Palma MD, Gulino G, Nasi PG, Pelizzo MR, Pezzullo L. Complications of Thyroid Surgery: Analysis of a Multicentric Study on 14,934 Patients Operated on in Italy over 5 Years. World J Surg 2004; 28(3): 271 - 276.

10. Menon VU, Sundaram KR, Unnikrishnan AG, Jayakumar $\mathrm{RV}$, Nair V, Kumar $\mathrm{H}$. High prevalence of undetected thyroid disorders in an iodine sufficient adult in south Indian population. J Indian Med Assoc 2009; 107:72- 7 .

11. Baldassarre RL, Chang DC, Brumund KT, Bouvet M. Predictors of Hypocalcemia after Thyroidectomy: Results from the Nationwide Inpatient Sample. ISRN Surgery 2012.1-7. Article ID 838614. http://dx.doi. org/10.5402/2012/838614.

12. Page C, Strunski V. Parathyroid risk in total thyroidectomy for bilateral, benign, multinodular goiter: Report of 351 surgical cases. J Laryngol Otol 2007; 121: 237-41.

13. Gonçalves AJ, Martins L, DeSouza TRB, Alves PJC, Schiola A, Rios OAB, Dos Santos AR. Clinical and laboratorial correlation of postoperative hypocalcemia after extensive thyroidectomy. Sao Paulo Med. J 1997; 115(1): 234 - 239. http://dx.doi. org/10.1590/S1516-31801997000100009.

14. Mirkine ND, Hooghe L, Geertruyden JV, Maertelaer VD. Hypocalcemia after Thyroidectomy. Predictors of hypocalcemia occurring after a total/near total thyroidectomy. Arch Surg 1992; 127(7): 854-858.

15. Iqbal M, Subhan A, Baig MS, Shah MS. Frequency of hypocalcemia in total thyroidectomy. J Surg Pak 2010; 15 (2):87-91.

16. Tredici EP, Grosso, Gibelli MA. Massaro C, Arrigoni $\mathrm{N}$, Tradati $\mathrm{N}$. Identification of patients at high risk for hypocalcemia after total thyroidectomy. Acta Otorhinolaryngol Ital. 2010; 30: 144-148. PMCID: PMC3185817.

17. Jisheng $\mathrm{H}$, Zhao N, Kong R, Wang D, Sun B, Wu L. Total thyroidectomy as primary surgical management for thyroid disease: surgical therapy experience from 5559 thyroidectomies in a less-developed region. World J Surg Onco 2016; 14(20): 1-7. DOI 10.1186/ s12957-016-0772-1.

18. Jong-Lyel $R$, Jae-Yong $P$, Chan II PMD. Total Thyroidectomy plus Neck Dissection in Differentiated Papillary Thyroid Carcinoma Patients: Pattern of Nodal Metastasis, Morbidity, Recurrence, and Postoperative Levels of Serum Parathyroid Hormone. Annals of Surgery: April 2007; 245(4): 604610. doi: 10.1097/01.sla.0000250451.59685.67.

19. Noordzij JP, Lee SL, Bernet VJ, Payne RJ, Cohen SM, McLeod IK, Hier MP, Black MJ, Kerr PD, Richards ML, Lo CY, Raffaelli M, Bellantone R, Lombardi CP, Cohen $\mathrm{JI}$, Dietrich MS. Early Prediction of Hypocalcemia after Thyroidectomy using Parathyroid Hormone: An Analysis of Pooled Individual Patient Data from Nine Observational Studies J Am coll Surg 2007; 06: .298302. DOI: http://dx.doi.org/10.1016/j.

20. Jong-Lyel R, Jae-Yong P, Chan-II P. Prevention of postoperative hypocalcemia with routine oral calcium and vitamin $D$ supplements in patients with differentiated papillary thyroid carcinoma undergoing total thyroidectomy plus central neck dissection. Cancer: 2009; 115(2): 251-258.

\section{AUTHORSHIP AND CONTRIBUTION DECLARATION}

\begin{tabular}{|c|c|c|c|}
\hline Sr. \# & Author-s Full Name & Contribution to the paper & Author $=$ s Signature \\
\hline 1 & Altaf Ahmed Talpur & $\begin{array}{l}\text { Design of the work \& acquisition } \\
\text { of data }\end{array}$ & \\
\hline 2 & Bheesham Kumar & Analysis \& interpretation of data & \\
\hline 3 & Ahsan Ali Laghari & Drafting the article & \\
\hline 4 & Abdul Qadeer Shikh & $\begin{array}{l}\text { Recising critically for important } \\
\text { intellectual content }\end{array}$ & \\
\hline 5 & Afzal Junejo & Final approval of the version & \\
\hline 6 & Ali Akber Ghumro & $\begin{array}{l}\text { Revised \& agreed to all aspects } \\
\text { of works }\end{array}$ & \\
\hline
\end{tabular}

